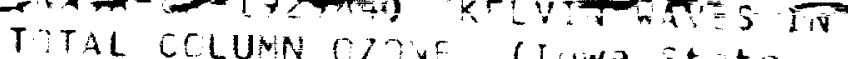

Ni3-25431

Univo of Scienco and

$10 \mathrm{p}$

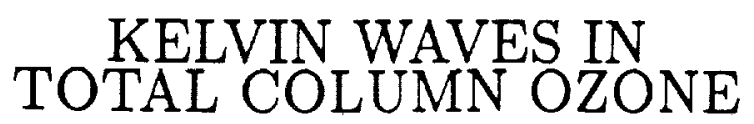

\author{
J. R. Ziemke and J. L. Stanford \\ Department of Physics \& Astronomy, Iowa State University \\ Ames, Iowa 50011
}

\begin{abstract}
Tropical Kelvin waves have been observed previously in ozone mixing ratio data from the SBUV (Solar Backscatter Ultraviolet) and LIMS (Limb Infrared Monitor of the Stratosphere) instruments on board the Nimbus-7 satellite. The present study investigates Kelvin wave features in total column ozone, using version 6 data from the Total Ozone Mapping Spectrometer (TOMS) instrument (also on board Nimbus-7). Results show eastward-propagating zonal waves 1-2 with periods $\sim 5-15$ days, amplitudes $\sim 3-5 \mathrm{DU}$, and latitudinal symmetry typical of Kelvin waves. A simplified model calculation suggests that the primary source for the perturbations is slow Kelvin waves in the lower-to-middle stratosphere. Maximum Kelvin wave signatures occur in conjunction with westward lowerto-middle stratospheric equatorial zonal winds [a quasi-biennial oscillation (QBO) wind modulation effect].
\end{abstract}

Submitted to Geophysical Research Letters, April 1993

Introduction

Many observational studies have been done on tropical Kelvin waves, with some of the earliest being Wallace and Kousky (1968), Maruyama (1969), and Angell et al.(1973). The present investigation examines TOMS total column ozone for signatures of these waves. As will be seen, the lower stratosphere appears to be the primary region responsible for Kelvin waves in total ozone.

Stratospheric Kelvin waves in ozone mixing ratio were studied by Prata (1990) using SBUV data for January 1979. That study reported upper stratospheric Kelvin waves in zonal waves 1 and 2 with periods $\sim 1$ week and vertical wavelengths $\sim 15 \mathrm{~km}$. A more recent study of Kelvin ozone waves by Randel and Gille (1991) examined LIMS data for January-February 1979 and SBUV data for January 1979-February 1986. Typical periods of upper stratospheric Kelvin waves were found to vary from 5 to 15 days with vertical wavelengths comparable to those found by Prata. Randel (1990), using LIMS data, showed that there are two primary regions of Kelvin waves in ozone mixing ratio: (1) the upper stratosphere (where photochemistry dominates), and (2) the lower stratosphere (where transport dominates). In the middle stratosphere $(\sim 10 \mathrm{hPa})$, Kelvin wave features are virtually nonexist because of vanishing vertical gradients in ozone mixing ratio. 
For investigating interannual variability of Kelvin wave signals in the lower stratosphere (where vertical wavelengths $\sim 6-10 \mathrm{~km}$ are common), there are problems with using the SBUV data. As noted by Randel and Gille, vertical resolution is $\sim 8-10 \mathrm{~km}$, and there is also an apparent effect by the processing algorithms that restricts detected vertical wavelengths to $27 \mathrm{~km}$ or larger. In contrast, the TOMS data, as will be seen, appear to be sensitive to Kelvin waves in the lower stratosphere.

Three 60-day case studies will be presented below, with each exhibiting features typical of tropical Kelvin waves. Two episodes are near solstice, beginning in July, and the third near equinox, beginning in March.

\section{Data and analysis}

This study uses TOMS version 6 daily data from the NASA/Goddard Space Flight Center made available on CD-ROM disk in a format of $1^{\circ}$ latitude by $1.25^{\circ}$ longitude bins, covering 1 November 1978 to 31 January 1992 . These data were regridded in this study onto a $5^{\circ} \times 5^{\circ}$ mesh extending from $85^{\circ} \mathrm{N}$ to $85^{\circ} \mathrm{S}$ in latitude and $180^{\circ}$ to $175^{\circ} \mathrm{W}$ in longitude. Further details concerning regridded TOMS data and spectral methods are discussed by Stanford and Ziemke (1993).

Monthly mean zonal winds from Singapore $\left(1.37^{\circ} \mathrm{N}, 103.92^{\circ} \mathrm{E}\right)$ [B. Naujokat, Free University of Berlin, personal communication] for years 1979-1991 at pressure levels 70, $50,40,30,20,15$, and $10 \mathrm{hPa}$ were used in this study.

Kelvin wave modeled amplitudes in total ozone

A model for tropical Kelvin waves in total column ozone is formulated using linearized forms of the thermodynamic and tracer continuity equations appropriate for Kelvin waves. The two equations are, respectively,

$$
\begin{gathered}
T_{t}^{\prime}+\bar{u} T_{x}^{\prime}+w^{\prime} H N^{2} / R=-T^{\prime} \tau^{-1} \\
\chi_{t}^{\prime}+\bar{u} \chi_{x}^{\prime}+w^{\prime} \bar{\chi}_{z}=-\Gamma \chi^{\prime}-\theta T^{\prime}
\end{gathered}
$$

where $T$ is absolute temperature, $\chi$ is volume mixing ratio, $H=$ scale height ( $7 \mathrm{~km}$ here), $R=$ gas constant $\left(287 \mathrm{~J} \cdot \mathrm{kg}^{-1} \mathrm{~K}^{-1}\right), N=$ buoyancy frequency (taken to be $\left.2 \times 10^{-2} \mathrm{~s}^{-1}\right), \tau^{-1}$ is a radiative damping coefficient, $\Gamma$ and $\theta$ are linear photochemical production/destruction parameters, the overbar denotes a zonal average, and subscripts denote partial differentiation. All other symbols are standard. Zonal mean wind $\bar{u}$ is a constant, but remains as a variable parameter in this model.

In (2) we use an approximate empirical form for the radiative damping coefficient given by $\tau^{-1}$ (units: $\left.\mathrm{s}^{-1}\right)=A\left(1-e^{-B / \lambda_{s}}\right) \cdot(z / 40)^{1.8}$, where $A=3.7 \times 10^{-6} \mathrm{~s}^{-1}, B=14.8(\mathrm{~km})$, $z$ is altitude $(\mathrm{km})$, and $\lambda_{z}=$ vertical wavelength $(\mathrm{km})$. This expression was constructed upon examining the diagrams of $\tau^{-1}$ in Fels $(1982,1984)$.

In (3), empirical forms for $\theta$ and $\Gamma$ are also used, given by $\theta=3.33 \times 10^{-16} \cdot(z-40)$, and $\Gamma=1.67 \times 10^{-8} \cdot(z-40)$, respectively. Here, $z$ is altitude in units $\mathrm{km}$, and units for $\theta$ 
( $\Gamma)$ are $\mathrm{K}^{-1} \mathrm{~s}^{-1}\left(\mathrm{~s}^{-1}\right)$. Both $\theta$ and $\Gamma$ are taken to be zero for $z<40 \mathrm{~km}$. These expressions are simple linear approximations to the $\theta$ and $\Gamma$ shown in Fig. 3 of Hartmann and Garcia (1979). Standard interpolated UMKEHR profiles (R. McPeters, NASA/GSFC, personal communication) for $250 \mathrm{DU}$ in the tropics were used to estimate $\bar{\chi}_{z}$ in (3). The bottom of UMKEHR level $j(j=0,1,2, \ldots, 10)$ is given by pressure $(1013.25) \cdot 2^{-j} \mathrm{hPa}$.

Perturbations in total column ozone (units: meters) are given by

$$
\Omega^{\prime}=0.772 \times \int_{0}^{\infty} d z \cdot \rho \cdot \chi^{\prime} \longrightarrow \int_{0}^{\infty} d z \cdot e^{-z / H} \cdot \chi^{\prime}
$$

where $\rho$, the total mass density, was approximated in (4) by $1.3 \cdot e^{-z / H}$ (units: $\mathrm{kg}-\mathrm{m}^{-3}$ ).

For induced Kelvin wave perturbations, the form of $\chi^{\prime}$ is taken to be the real part of $\chi^{\prime}(x, y, z, t)=\hat{\chi}(y, z) \cdot e^{z / 2 H} \cdot e^{i(k x+m z-\omega t)}$, where the exponential terms were chosen to balance those of linear Kelvin wave temperature perturbation solutions (see, for example, Andrews et al., 1987). Based on observations, Kelvin wave temperature disturbances in this model were all taken to be $2.8 \mathrm{C}^{\circ}$ at 4 scale heights.

From (4), peak perturbation amplitudes in total column ozone are found to be $\sim 1-2$ $\mathrm{DU}$ for eastward propagating linear Kelvin waves 1 or 2 , with vertical wavelengths 8-32 $\mathrm{km}$ (see Fig.1). This linear model appears to break down for short vertical wavelengths; only wavelengths longer that $8 \mathrm{~km}$ are plotted in the figure. According to Bhartia et al. (1984), local errors in unfiltered TOMS data are $\sim 1-2 \%$. In comparison with the model, upper stratospheric Kelvin waves with long vertical wavelengths ( $>15 \mathrm{~km})$ would induce amplitudes too small to be detected in TOMS data.

\section{Kelvin wave signatures in TOMS}

TOMS power spectra for fast (periods $<15$ days) zonal waves 1-2 are shown in Fig.2. Three case examples were selected for study here, and are indicated by E1, E2, and E3; each is 60 days in length and starting dates are 1 July 1981, 15 July 1984, and 1 March 1987, respectively. Monthly mean $30 \mathrm{hPa}$ QBO zonal winds reveal an apparent out of phase relationship with the eastward propagating components. A recent study by Shiotani and Horinouchi (1993) found a similar relationship, but between $70 \mathrm{hPa}$ easterly zonal QBO winds and lower stratospheric Kelvin wave activity. The similarity suggests that eastward waves 1-2 in Fig.2 are likely due to lower stratospheric Kelvin waves. This is supported further in the results by Randel and Gille (1991) which found a characteristic semiannual variability of Kelvin waves in the upper stratosphere and lower mesosphere with maximum activity near solstice. In contrast, semiannual variation of spectral amplitudes is not apparent in Fig.2.

Kelvin wave signatures in total ozone are expected to exhibit eastward propagating waves 1 or 2 with maximum amplitudes along the equator, and periods between 4 and 15 days. The spectra in Fig.3a show eastward waves 1-2 dominating all three episodes along the equator, with periods $\sim 5-15$ days. The line of constant phase speed shown in each frame is centered through the zonal wavenumber contributing most to total amplitude. Figure $3 \mathrm{~b}$ shows structures typical of Kelvin waves, with eastward components exhibiting 
strong meridional symmetry with a relative maximum along the equator. All three cases could be lower stratospheric "slow" Kelvin waves since phase speeds appear to be less than $\sim 40 \mathrm{~ms}^{-1}$ (see, for example, Wallace and Kousky, 1968). Faster phase speeds (exceeding $60 \mathrm{~ms}^{-1}$ ) are more generally found in the upper stratosphere (Hirota, 1978; Salby et al., 1984).

Simple zonal wind advection of ozone does not explain these results. Monthly mean zonal winds at Singapore (not shown) for pressure levels $10,15,20,40,50$, and $70 \mathrm{hPa}$ indicate that westerly winds occur only at the lowest and highest altitudes for episodes E1 and E3, respectively, with values less than $12 \mathrm{~ms}^{-1}$. Even at $12 \mathrm{~ms}^{-1}$, the period of eastward propagating zonal wave 1 (2) would be 38 (19) days, which is roughly twice the observed values shown in Fig.3.

Figure 4 shows Hovmöller diagrams for episodes E1-E3. Bandpass filters were applied to retain the primary equatorial spectral responses shown in Fig.3 (no eastward/westward filtering is employed). Oscillation periods are $\sim 6-10$ days for each episode when amplitudes appear largest (exceeding $3 \mathrm{DU}$ ). Note eastward phase movement of strongest amplitudes, consistent with Kelvin wave dynamics.

It is a possible that tropical clouds accompanying Kelvin waves could induce some of the features found here because roughly $10 \%$ of total column ozone is thought to lie below the tropopause and TOMS retrievals depend on the presence or absence of clouds. However, the model calculations presented above suggest that stratospheric ozone alone could account for the perturbation amplitudes observed.

Eastward bandpass-filtered root-mean-square amplitudes (combined zonal waves 1-2) calculated for the three events are shown in Fig.5. In each case an equatorial maximum is evident, with largest amplitudes for E2 and E3 near the African continent, and for E1, along the western Pacific Ocean region. Longitudinal differences between episodes E1-E3 could be caused by different tropical forcing regions, the effects of clouds and stratospheric winds, background gradients in ozone, or a combination of these.

\section{Summary}

1. Tropical Kelvin wave signatures in total column ozone are found in three separate case studies. Observed periods for zonal waves 1-2 were $\sim 5-15$ days, and amplitudes exceeded 3, and sometimes 5 DU. While tropical clouds associated with Kelvin waves could contribute to the observed amplitudes, a model calculation (independent of any cloud effects) shows that lower stratospheric ozone perturbations alone are sufficient to induce the observed TOMS Kelvin wave amplitudes.

2. A strong relationship is found between the $30 \mathrm{hPa} \mathrm{QBO}$ wind and equatorial eastward zonal waves 1-2 in total ozone, in contrast to semiannual variations in upper stratospheric Kelvin ozone waves found by earlier investigators. This implies that eastward Kelvin wave features in TOMS data are influenced more by Kelvin waves in the lower-tomiddle stratosphere than at higher altitudes. Furthermore, a previous study using 15 years of tropical rawinsonde data showed that maximum Kelvin wave activity in the lower stratosphere occurs when the QBO zonal wind easterlies at $70 \mathrm{hPa}$ are maximum. 
Acknowledgments. We thank Ms. Patricia T. Guimaraes, Dr. Richard D. McPeters, Dr. Arlin J. Krueger, and the members of the NASA TOMS NIMBUS Experiment and Information Processing Teams, and the National Space Science Data Center for providing the TOMS data on CD-ROM disc. We have enjoyed several helpful conversations with Dr. W. J. Randel. This work was supported by National Aeronautics and Space Administration Grant NAG 5-1519.

\section{References}

Andrews, D. G., J. R. Holton, and C. B. Leovy, 1987: Middle Atmosphere Dynamics, Academic Press, Inc., New York. pp. 489.

Angell, J. K., G. F. Cotton, and J. Korshover, 1973: A climatological analysis of oscillations of Kelvin wave period at $50 \mathrm{mb}$. J. Atmos. Sci., 90, 13-24.

Bhartia, P. K., K. F. Klenk, C. K. Wong, D. Gordon, and A. J. Fleig, 1984: Intercomparison of the Nimbus 7 SBUV/TOMS total ozone data sets with Dobson and M83 results. J. Geophys. Res., 89, 5239-5247.

Fels, S. B., 1982: A parameterization of scale-dependent radiative damping rates in the middle atmosphere. J. Atmos. Sci., 99, 1141-1152.

Fels, S. B., 1984: The radiative damping of short vertical scale waves in the mesosphere. J. Atmos. Sci., 41, 1755-1764.

Hartmann, D. L., and R. L. Garcia, 1979: A mechanistic model of ozone transport by planetary waves in the stratosphere. J. Atmos. Sci., 96, 350-364.

Hirota, I., 1978: Equatorial waves in the upper stratosphere and mesosphere in relation to the semiannual oscillation of the zonal wind. J. Atmos. Sci., 95, 714-722.

Maruyama, T., 1969: Long-term behavior of Kelvin waves and mixed Rossby-gravity waves. J. Meteor. Soc. Japan, 47, 245-254.

Prata, A. J., 1990: Travelling waves in Nimbus-7 SBUV ozone measurements: Observations and theory. Q. J. R. Meteor. Soc., 116, 1091-1122.

Randel, W. J., 1990: Kelvin wave-induced trace constituent oscillations in the equatorial stratosphere. J. Geophys. Res., 95, 18641-18652.

Randel, W. J., and J. C. Gille, 1991: Kelvin wave variability in the upper stratosphere observed in SBUV ozone data. J. Atmos. Sci., 48, 2336-2349.

Stanford, J. L., and J. R. Ziemke, 1993: Rossby-gravity waves in tropical total column ozone. Submitted to Geophys. Res. Lett.

Salby, M. L., D. L. Hartmann, P. L. Bailey, and J. C. Gille, 1984: Evidence for equatorial Kelvin modes in Nimbus-7 LIMS. J. Atmos. Sci., 41, 220-235.

Shiotani, M., and T. Horinouchi, 1993: Kelvin wave activity and the quasi-biennial oscillation in the equatorial lower stratosphere. J. Meteor. Soc. Japan, 71, 175-181.

Wallace, J., and V. Kousky, 1968: Observational evidence of Kelvin waves in the tropical stratosphere. J. Atmos. Sci., 25, 900-907. 


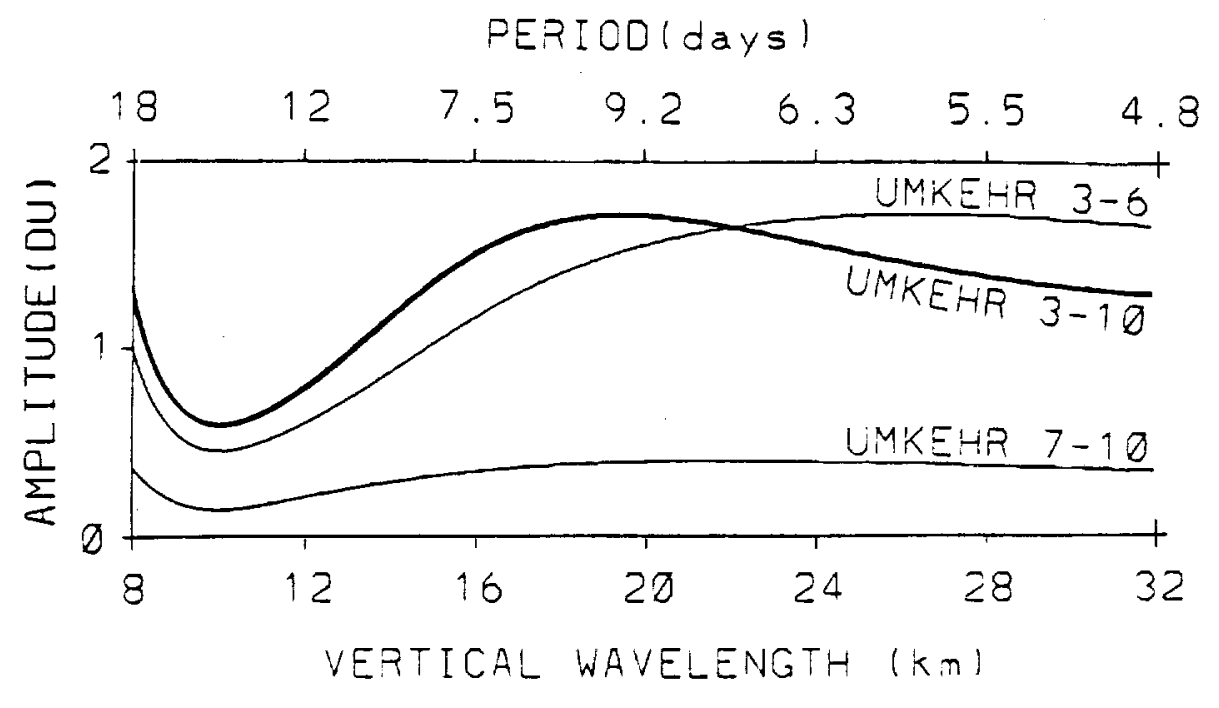

FIGURE 1. Peak amplitudes in modeled zonal wave 1 (wave 2 results are the same) Kelvin wave perturbation amplitudes (DU) in total column ozone plotted vs. vertical wavelength (bottom; units $\mathrm{km}$ ) and intrinsic $(\bar{u}=0)$ period (top; units days). UMKEHR levels $3-6,7-10$, and $3-10$ refer to $5.3-127 \mathrm{hPa}, 0-5.3 \mathrm{hPa}$, and $0-127 \mathrm{hPa}$, respectively. The latter is included for comparing cancellation effect(s) between the upper and lower stratosphere. 

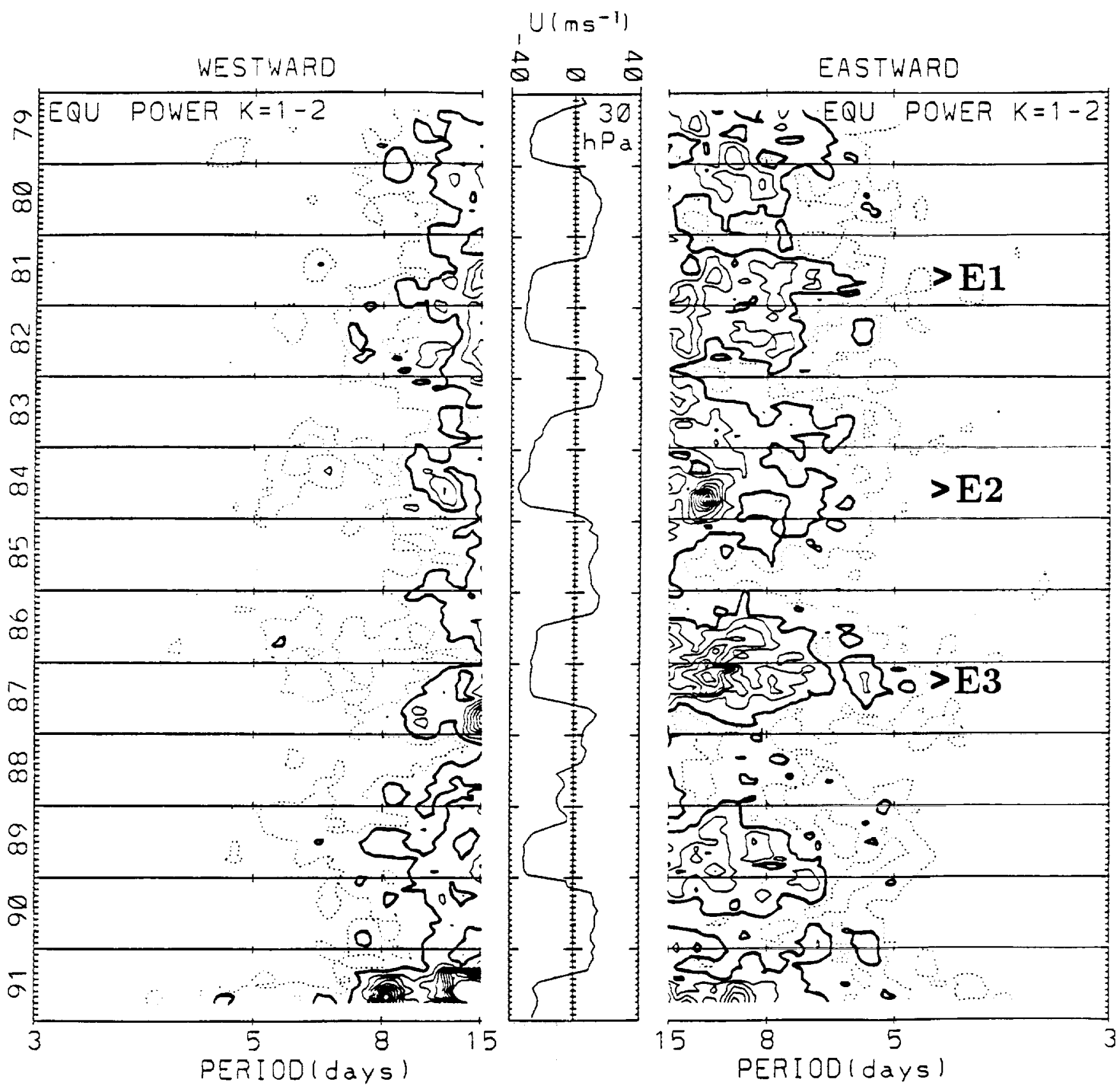

FIGURE 2. Calculated westward/eastward TOMS power spectra covering 1979-1991 for combined zonal waves $1-2$ along the equator, and $30 \mathrm{hPa}$ monthly mean zonal winds (units $\mathrm{ms}^{-1}$ ) from Singapore (middle). A 180-day window was stepped forward in time at one-month intervals to compute spectra. Only the largest frequencies are shown, with periods in days indicated $(15,8,5$, and 3 days). Solid (dashed) contours in spectra are $0.02,0.04,0.06, \ldots(0.01)$ with 0.02 darkest; units are $\mathrm{DU}^{2}$-day. Symbols E1-E3 identify three 60-day case studies discussed in text. 


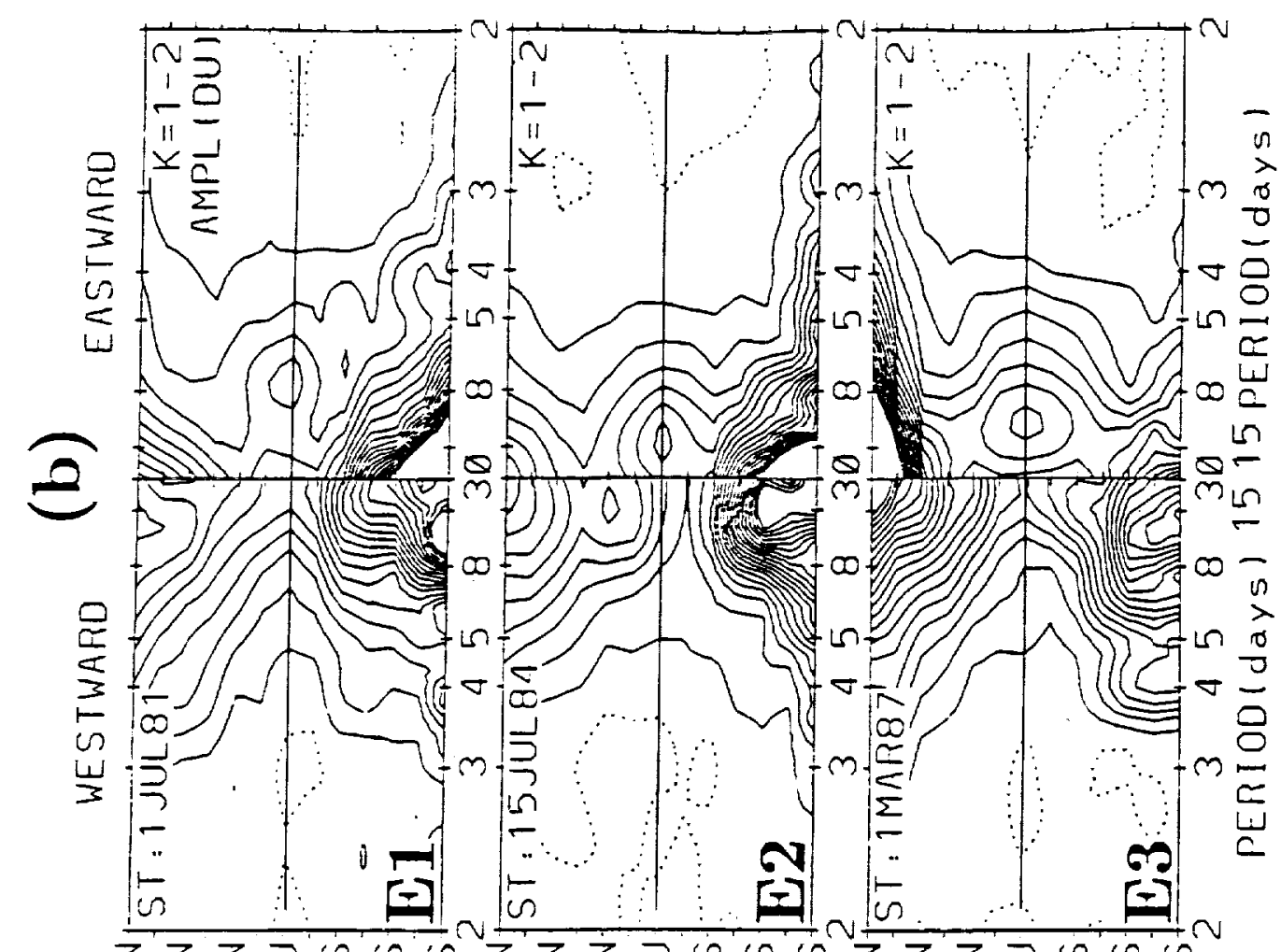

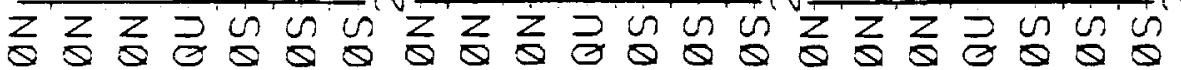
$m \sim-u-N m m N-u-N m m \sim-w-N m$ $\exists O \cap \perp I \perp \forall 7 \quad \exists O \cap \perp I \perp \forall 7 \quad \exists O \cap \perp I \perp \forall 7$

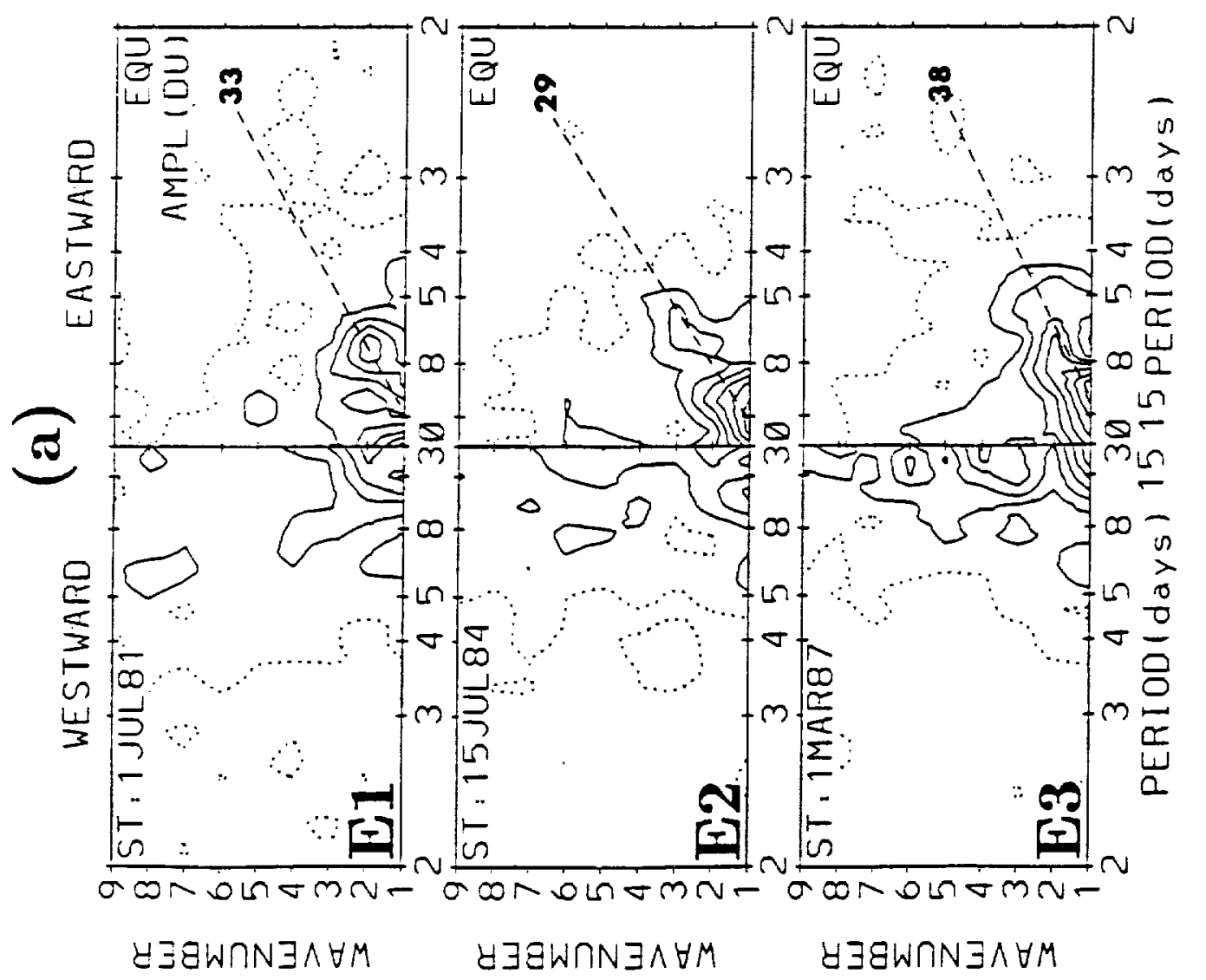

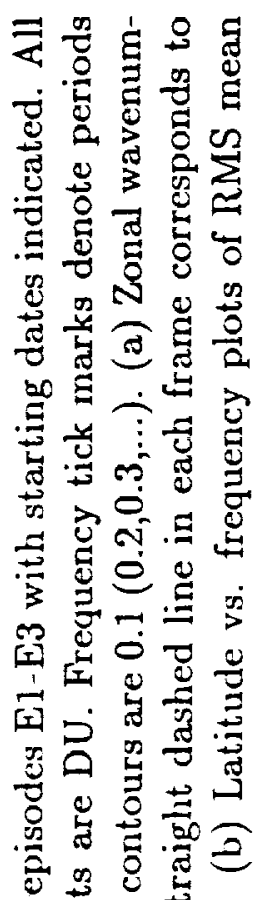

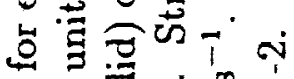

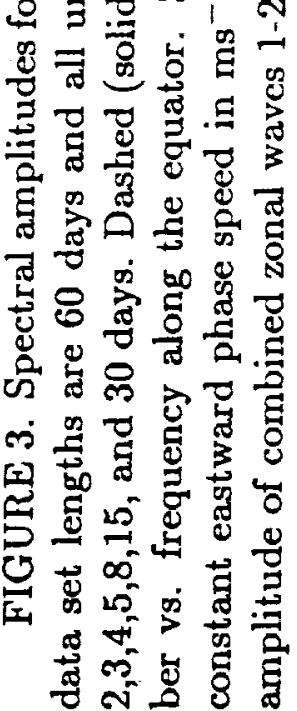



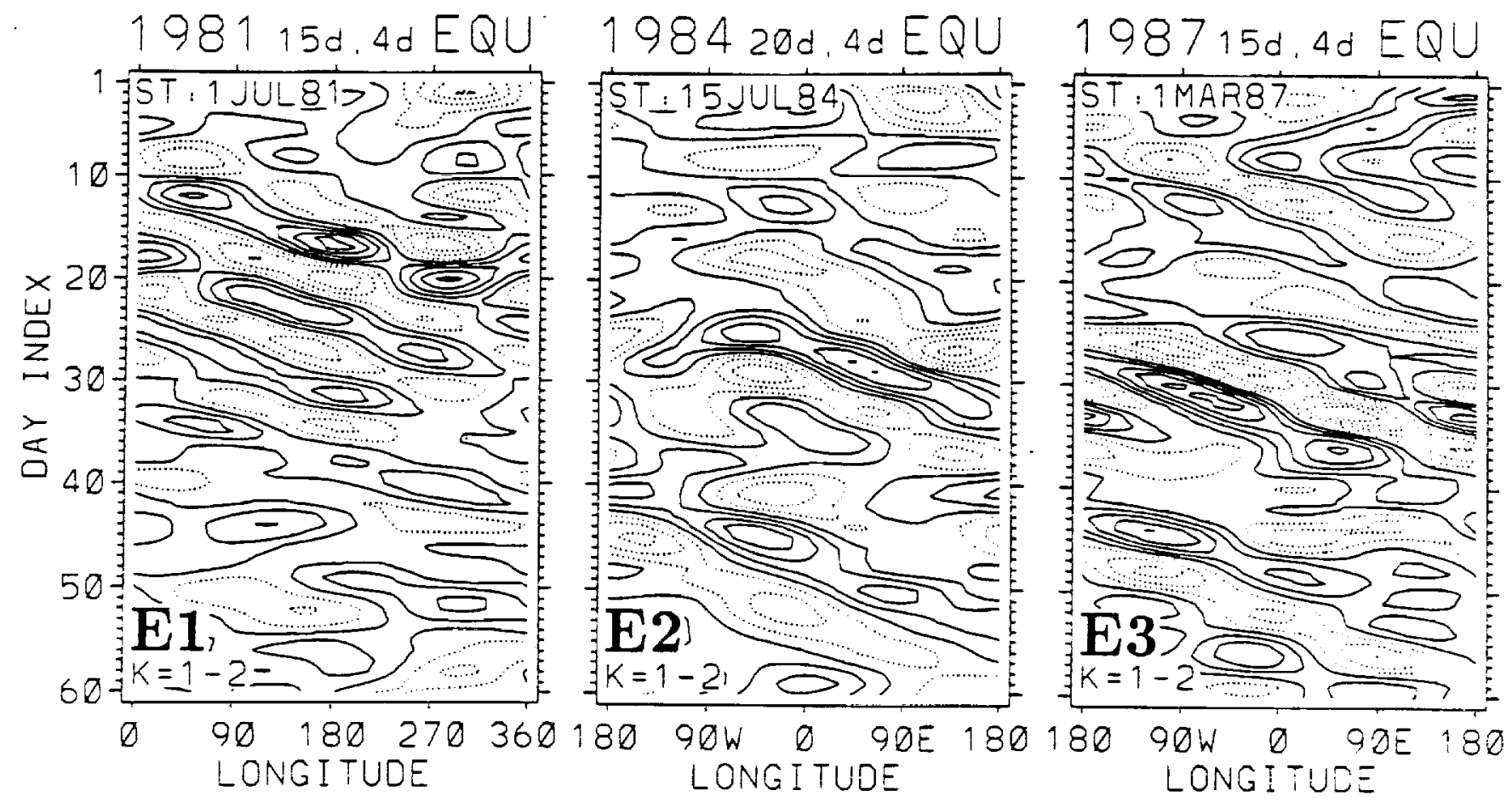

FIGURE 4. Time vs. longitude Hovmöller diagrams for case studies E1-E3. Spatial filtering: zonal waves 1-2. E1 and E3 (E2) used a bandpass filter response with halfamplitudes at 15 and 4 -day ( 20 and 4-day) periods. Solid (dashed) contours begin at zero $(-1)$ and increment (decrement) by 1 . Units: DU. 


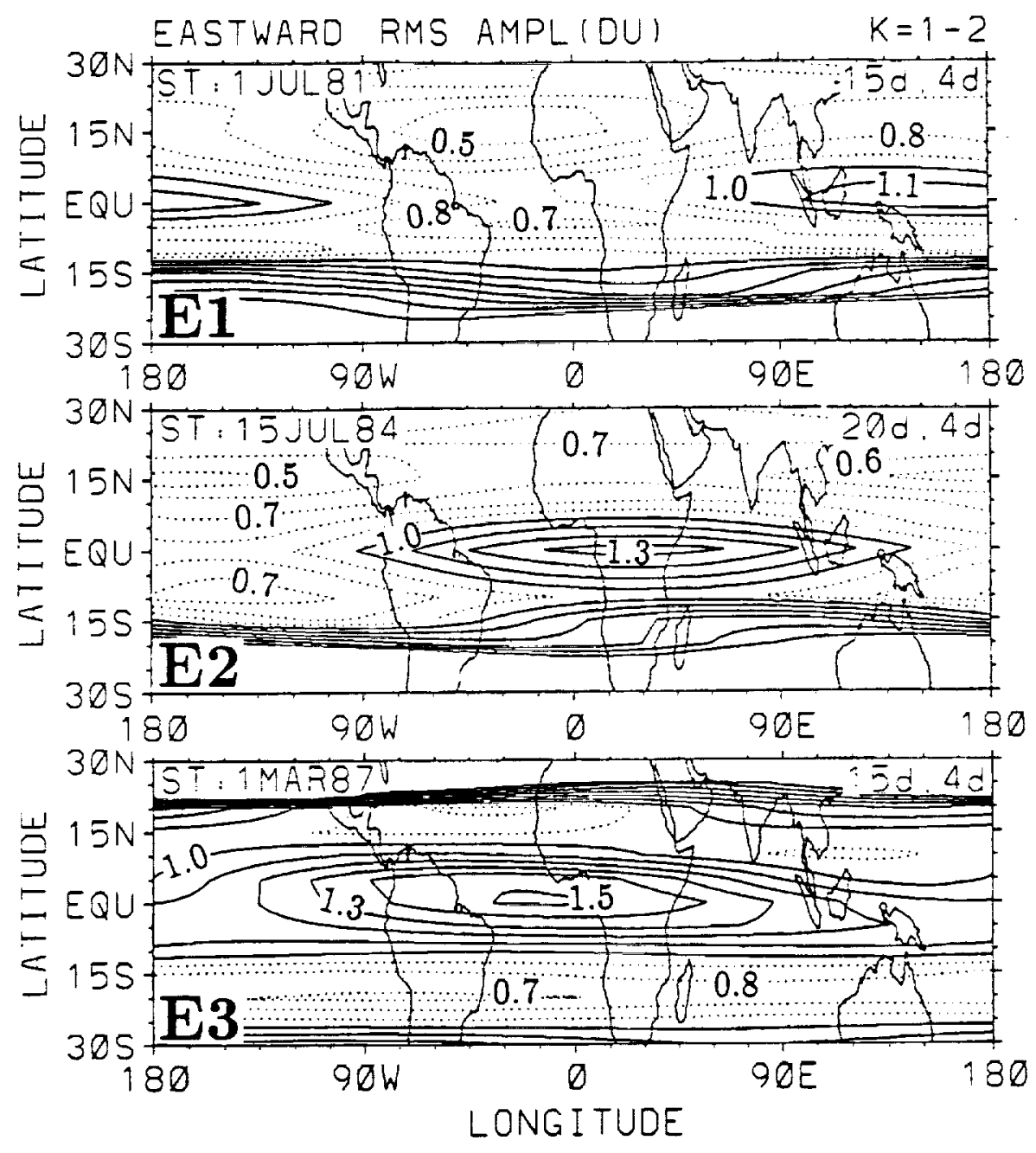

FIGURE 5. Latitude vs. longitude eastward root-mean-square amplitude plots for case studies E1-E3. Amplitudes are calculated from the eastward components of the data sets shown in Fig.4. Solid (dashed) contours begin at $1.0(0.9)$ and (increment) decrement by 0.1 . Units: DU. 